\title{
MODEL ADDIE BERBASIS KEARIFAN LOKAL ENDE-LIO UNTUK MENINGKATKAN KUALITAS PERKULIAHAN DESAIN PEMBELAJARAN IPA PADA MAHASISWA PGSD UNIFLOR
}

\author{
Nining Sar'iyyah ${ }^{1}$, Adi Neneng Abdullah ${ }^{2}$, Chatarina Novianti ${ }^{3}$
Universitas Flores ${ }^{\mathbf{3}, 2,3}$ \\ sariyyah.nining@gmail.com ${ }^{1}$
}

\begin{abstract}
ABSTRAK
Penelitian ini bertujuan untuk meningkatkan kualitas perkuliahan desain pembelajaran IPA pada mahasiswa PGSD Universitas Flores melalui model ADDIE berbasis kearifan lokal. Penelitian ini merupakan penelitian tindakan kelas dengan tahapan perencanaan, tindakan, observasi dan refleksi. Data yang dikumpulkan terdiri dari produk perangkat pembelajaran IPA berbasis kearifan lokal Ende-Lio, aktifitas dan kreatifitas mahasiswa. Hasil penelitian, evaluasi produk pada siklus I mencapai persentase rata-rata sebesar $70 \%$. Siklus II terjadi peningkatan rata-rata $92 \%$. Begitupun halnya aktifitas dan kreatifitas yang teramati menunjukkan adanya peningkatan dari siklus I kesiklus II. Simpulan, model ADDIE berbasis kearifan lokal Ende-Lio dapat meningkatkan kemampuan mahasiswa dalam mendesain pembelajaran IPA.
\end{abstract}

Kata Kunci: Model ADDIE, KearifanLokal Ende-Lio, Desain Pembelajaran

\section{ABSTRACT}

The study aims to improve the quality of learning science in designing at PGSD students of Universitas Flores through ADDIE model with local wisdom based. The research was a classroom action research with some steps such as planning, action, observation and reflection. The data included science learning product with EndeLio local wisdom based, students activities and creativity. The result was that the product evaluation in cycle I reached 70\%. In cycle II, the percentage improved for 92\%. The activities and creativity were also improved. In conclusion, ADDIE model with Ende-Lio local wisdon based can improve students ability in designing science learning.

Keywords: ADDIE model, local wisdom Ende-Lio, teaching design. 


\section{PENDAHULUAN}

Mata Kuliah Desain Pembelajaran IPA di SD merupakan mata kuliah yang memfasilitasi mahasiswa dalam membuat berbagai rencana yang berkaitan dengan tugas utama dari seorang guru. Perkuliahan ini bertujuan agar mahasiswa memiliki pengetahuan tentang konten materi IPA di sekolah dasar dan memiliki pengetahuan pedagogik, serta menerapkan pengetahuan-pengetahuan tersebut dalam merancang perangkat pembelajaran IPA di sekolah dasar.

Setiap proses pembelajaran ataupun perkuliahan lazimnya memiliki kelemahan terhadap tantangan perubahan. Seperti halnya dalam perkuliahan desain pembelajaran IPA, mahasiswa PGSD Uniflor masih kesulitan dalam mengembangkan desain pembelajaran IPA berbasis kurikulum 2013. Walaupun keberadaan kurikulum tersebut bukanlah hal yang baru semenjak tahun 2013, namun bagi para mahasiswa belum sepenuhnya memahami dan mampu mengembangkan perangkat pembelajaran IPA dengan baik. Proses mendesain masih terpusat pada buku guru dan buku siswa yang dibagikan secara gratis oleh negara.

Pada kurikulum 2013 di sekolah dasar, mata pelajaran IPA dijalankan secara terpadu di kelas tinggi. Menurut Nollmeyer. dkk (2016) pembelajaran terpadu mengkoneksikanbeberapadisiplinilmu, kontendan skill.Pembelajaranterpadubertujuan agar siswa mampu memahami pengetahuan secara kontekstual dan holistik (Nadiyah \& Faaizah. (2015). Untuk dapat mewujudkan proses belajar secara kontekstual dan holistic, penerapan pembelajaran seyogyanya dihubungkan dengan lingkungan di sekeliling siswa. Hal ini dimaksudkan agar proses belajar dapat lebih bermakna atau dapat diterapkan dalam setiap aspek kehidupan siswa. Salah satu cara unik adalah dengan menghubungkan kearifan lokal di sekeliling siswa. Cara ini juga dapat dikatakan efektif untuk memupuk kecintaan siswa terhadap budaya daerah yang semakin lama mulai tergerus modernitas.

Menggali kebudayaan lokal khususnya kearifan lokal dalam masyarakat suku Ende-Lio dan mengintegrasikan dalam pembelajaran IPA di sekolah dasar tidaklah sesulit yang dibayangkan. Ada beraneka kearifan lokal berupa tanaman lokal dan makanan lokal, tenun ikat, teknologi dan peralatan, kegiatan menangkap ikan dan bertani, serta kegiatan meramu obat-obatan dan kecantikan. yang telah dipakai oleh nenek moyang suku Ende-Lio (suku yang mendiami wilayah kabupaten Ende, Nusa Tenggara Timur) secara turun temurun. Integrasi kearifan lokal Ende-Lio tersebut dapat diterapkan dalam perencanaan pembelajaran melalui model ADDIE.

Model ADDIE merupakan sebuah akronim dari lima tahapan yang umumnya terdapat dalam proses desain pembelajaran. Tahapan tersebut terdiri dari Analysis, Design, Development, Implementation dan Evaluation (Holden, 2015). Model ini telah banyak diteliti untuk mengatasi berbagai persoalan terkait desain pembelajaran. Hal ini telah dibuktikan dalam penelitian Muruganantham (2015), Hsu dkk (2014), Whipasith, Narumol dan Sumalee (2016) serta Nadiyah dan Faaizah (2015).

\section{METODE PENELITIAN}

Penelitian ini merupakan penelitian tindakan kelas (PTK). Penelitian tindakan kelas merupakan suatu bentuk refleksi diri yang bermanfaat bagi guru untuk 
meningkatkan pemahaman tentang praktik pembelajaran dan mengatasi masalah pembelajaran di dalamkelas (Hien, 2016). Penelitian ini berlangsung selama lima bulan. Subyek penelitian adalah mahasiswa semester 5 PGSD Uniflor yang menempuh program mata kuliah desain pembelajaran IPA. Sedangkan prosedur penelitian penelitian tindakan kelas ini mengacu pada desain PTK Kemis \& Mc Taggart (Fahmidkk, 2018) yang meliputi: perencanaan, pelaksanaan, pengamatan dan refleksi.

Tahap pertama, perencanaan difokuskan pada persiapan rencana perkuliahan beserta lembar penilaian produk perangkat pembelajaran yang akan dihasilkan mahasiswa. Perencanaan juga meliputi persiapan instrumen penelitian yakni lembar observasi dan lembar angket serta kamera untuk merekam proses tindakan.

Tahapan tindakan dilakukan dengan menerapkan model ADDIE berbasis kearifan lokal. langkah penerapan dilakukan sesuai sintaksis dalam model ADDIE yakni Analisis, Desain, Development (pengembangan), Implementasi dan Evaluasi. Langkahpertama, analisis merupakan tahap pengumpulan informasi mengenai kearifan lokal Ende-Lio serta relevansinya dengan konten materi IPA sesuai kurikulum 2013.Kedua,desain adalah tahap dilakukan rancangan awal perangkat pembelajaran IPA berbasis kearifan lokal.Ketiga adalah tahap pengembangan yakni dilakukan proses validasi dan revisi oleh validator. Keempat, tahapan implementasi merupakan tahap uji coba terhadap perangkat pembelajaran yang direncanakan.Langkah terakhir adalah evaluasi yakni untuk melihat apakah pembelajaran yang dikembangkan berhasil sesuai harapan atau tidak.

Selama tahap tindakan berlangsung, tahapan observasi juga ikut serta dilakukan. Dalam penelitian ini, proses observasi dilakukan oleh dua orang observer yang merekam proses perkuliahan dengan menerapkan model ADDIE berbasis kearifan lokal. Observasidilakukandenganmenggunakan instrument pengamatan yang telahdisiapkan.

Tahapterakhiradalahrefleksi.Refleksi dilakukan dalam rangka menemukan kelemahan dan kekurangan pada praktik pembelajaran yang dilakukan dan untuk mencari pemecahan maupun penguatan-penguatan terhadap pembelajaran yang masih dipandang kurang optimal. Tujuannya adalah untuk menemukan perbaikan-perbaikan apa yang perlu dilakukan pada proses pembelajaran berikutnya.

Penelitianinibertujuanuntukmenangkap data tentang kualitas perkuliahan desain pembelajaran IPAsetelahditerapkan model ADDIE berbasiskearifanlokalEndeLio. Data tersebut terdiri dari produkperangkat pembelajaran, sertaaktifitas dan kreatifitas mahasiswa. Data-data tersebut diambil dengan teknik dokumentasi, observasi dan angket. Dokumentasi digunakan untuk mengumpulkan data tentang produk-produk perangkat pembelajaran yang dihasilkan setelah diterapkan model ADDIE berbasis kearifan lokal Ende-Lio. Sedangkan Observasi dan angket digunakan untuk merekam data tentang aktifitas dan kreatifitasmahasiswaselamaperkuliahanberlangsung.

Data tersebut kemudian dianalis dengan membandingkan persentase ketuntasan produk, aktivitas dan kreatifitas sesuai target pencapaian penelitian dalam Tabel 1. 
Tabel 1 Target PencapaianPenelitian

\begin{tabular}{ccc}
\hline Ketuntasan & $\begin{array}{c}\text { Persentase rata- } \\
\text { rata }(\%)\end{array}$ & Keterangan \\
\hline Produk & 90 & Tuntas \\
Aktifitas & $<80$ & Aktifatausangataktif \\
Kreatifitas & $<80$ & Kreatifatausangatkreatif \\
\hline
\end{tabular}

Berdasarkan Tabel 1, apabila rata-rata ketuntasan produk telah mencapai $90 \%$ dan aktifitas serta kreatifitas mahasiswa telah mencapaiataumelebihi $80 \%$ maka prosedur tindakan akan dihentikan dengan kesimpulan model ADDIE dapat meningkatkan kualitas perkuliahan desain pembelajaran IPA pada mahasiswa PGSD semester 5 .

\section{HASIL PENELITIAN}

\section{TemuanPenelitian}

Penelitian ini bertujuan untuk meningkatkan kualitas perkuliahan desain pembelajaran IPA setelah diterapkan model ADDIE berbasis kearifan lokal Ende-Lio. Kualitas perkuliahan desain pembelajaran IPA yang dimaksud meliputi produk perangkat pembelajaran IPA berbasis kearifan lokal Ende-Lio, serta kreatifitas dan aktifitas mahasiswa selama perkuliahan berlangsung. Adapun hasil penelitian selama dua siklus dapat dilihat pada Tabel 2danTabel 3.

Tabel 2 PencapaianKetuntasanSiklus I

\begin{tabular}{ccc}
\hline Ketuntasan & Persentase rata-rata (\%) & Keterangan \\
\hline Produk & 70 & BelumTuntas \\
Aktifitas & 81 & Aktif \\
Kreatifitas & 71 & CukupKreatif \\
\hline
\end{tabular}

Tabel 3 PencapaianKetuntasanSiklus II

\begin{tabular}{ccc}
\hline Ketuntasan & Persentase rata-rata $(\%)$ & Keterangan \\
\hline Produk & 92 & Tuntas \\
Aktifitas & 96 & SangatAktif \\
Kreatifitas & 81 & Kreatif \\
\hline
\end{tabular}

Tabel 2 danTabel 3 menunjukkan terdapat peningkatan ketuntasan produk, aktivitas maupun kreatifitas dari siklus I ke siklus II. Untuk produk pada siklus I mencapai persentase rata-rata sebesar $70 \%$ dan meningkat menjadi $92 \%$ pada siklus II. Aktifitas dan kreatifitas berturut-turut meningkat dari $81 \%$ dan $71 \%$ pada siklus I menjadi $96 \%$ dan $81 \%$ pada siklus II. Merujuk pada Tabel 1, perolehan ketuntasan tersebut telah melebihi target yang diinginkan sehingga dihentikan pada siklus II. Dengan demikian, model ADDIE berbasis kearifan lokal Ende-Lio dapat meningkatkan kualitas perkuliahan desain pembelajaran IPA pada mahasiswa PGSD Uniflor.

Selain pencapaian ketuntasan, terdapat pula produk perangkat pembelajaran IPA berbasis kearifan lokal Ende-Lio yang dihasilkan. Adapun konten kearifan lokal 
Ende-Lio yang diintegrasikan kedalam produk perangkat pembelajaran tersebut dapat dilihat pada Tabel 4.

Tabel 4

ProdukPerencanaanPembelajaran IPA BerbasisKearifanLokalEnde-Lio

\begin{tabular}{|c|c|c|c|c|}
\hline Kelompok & Kelas & Tema & Kontenmateri IPA & KearifanLokal \\
\hline 1 & 4 & $\begin{array}{l}\text { IndahnyaKebersa } \\
\text { maan }\end{array}$ & Bunyi & $\begin{array}{l}\text { AlatmusiktradisionalsukuEn } \\
\text { de-Lio }\end{array}$ \\
\hline 2 & 4 & $\begin{array}{l}\text { SelaluBerhematE } \\
\text { nergi }\end{array}$ & Energi & $\begin{array}{l}\text { ObyekalamEnde-Lio yang } \\
\text { berpotensisebagaisumberlist } \\
\text { rik (PLTA dan PLTG), } \\
\text { PermainanTradisonal }\end{array}$ \\
\hline 3 & 4 & $\begin{array}{l}\text { Berbagaipekerjaa } \\
\mathrm{n}\end{array}$ & $\begin{array}{l}\text { hubunganantarasumb } \\
\text { erdayaalamdenganlin } \\
\text { gkungan, teknologi, } \\
\text { danmasyarakat }\end{array}$ & TenunIkatEnde-Lio \\
\hline 4 & 4 & Pahlawanku & $\begin{array}{l}\text { karya/model yang } \\
\text { memanfaatkansifat- } \\
\text { sifatcahaya }\end{array}$ & $\begin{array}{l}\text { PenerangantradisionalsukuE } \\
\text { nde-Lio }\end{array}$ \\
\hline 5 & 4 & $\begin{array}{l}\text { MakanankuSehat } \\
\text { danBergizi }\end{array}$ & $\begin{array}{l}\text { Sumberdayaalamdanp } \\
\text { emanfaatannyaolehm } \\
\text { asyarakat }\end{array}$ & MakananLokalEnde-Lio \\
\hline 6 & 5 & $\begin{array}{l}\text { Benda-benda di } \\
\text { LingkunganSekit } \\
\text { ar }\end{array}$ & $\begin{array}{l}\text { Perubahan yang } \\
\text { terjadi di alam, } \\
\text { hubungannyadenganp } \\
\text { enggunaansumberday } \\
\text { aalam, danpengaruh } \\
\text { kegiatanmanusiaterha } \\
\text { dapkeseimbanganling } \\
\text { kungansekitar }\end{array}$ & $\begin{array}{l}\text { Ritual adatEnde-Lio yang } \\
\text { berhubungandengansumberd } \\
\text { ayaalam (ritual perladangan, } \\
\text { dll) }\end{array}$ \\
\hline 7 & 5 & $\begin{array}{l}\text { BanggaSebagaib } \\
\text { angsa Indonesia }\end{array}$ & $\begin{array}{l}\text { pemanfaatanbagiantu } \\
\text { mbuhan di } \\
\text { sekitarnyabagimanusi } \\
\text { a }\end{array}$ & $\begin{array}{l}\text { Tanamanobat- } \\
\text { obatanlokalEndeLio }\end{array}$ \\
\hline
\end{tabular}

\section{Pembahasan}

Penelitian ini diawali dengan permasalahan lemahnya kualitas perkuliahan desain pembelajaran IPA pada mahasiswa semester 5 PGSD. Hal ini terindikasi pada rendahnya aktifitas dan kreatifitas mahasiswa dalam mengembangkan perangkat pembelajaran IPA SD. Produk perangkat pembelajaran IPA yang dihasilkan mahasiswa masih terfokus pada buku guru danbukusiswa. Setelah diterapkan model ADDIE berbasis kearifan lokal Ende-Lio, terjadi peningkatan produk, aktifitas dan kreatifitas.

Model ADDIE terdiri atas tahapan analisis, desain, pengembangan, implementasi dan evaluasi (Cheung, 2016). Tahap analisis terdiri atas analisis kebutuhan dan analisis kinerja. Dalam konteks penelitian ini, tahapan analisis menginstruksikan mahasiswa agar focus menggali konten kearifan lokal Ende-lio yang relevan dengan materi pembelajaran IPA SD. Pada tahapan ini mahasiswa dibagi ke dalam 7 kelompok dan terlihat aktif dan cukup kreatif mengerjakan tugas 
sesuai instruksi. Baik siklus I maupun siklus II, pada tahapan ini tidak banyak kelompok yang membutuhkan bimbingan dosen pengampu mata kuliah.

Tahapan desain dan tahapan pengembangan cukup memakan waktu yang panjang pada siklus I. Dalam tahapan ini dikembangkan rancangan awal perangkat pembelajaran kemudian dilakukan validasi. Banyak kelompok yang bingung dalam memvalidasikan produk perangkat pembelajaran yang telah dibuat. Sehingga proses bimbingan pada langkah ini dilakukan dengan lebih intens. Berdasarkan kekurangan dalam siklus I tersebut, dilakukan perbaikan pada siklus II dengan menyiapkan instrument validasi yang seragam untuk memperlancar proses tersebut. Tahapan ini menghasilkan 7 rancangan awal perangkat pembelajaran IPA berbasis kearifan lokal Ende-Lio.

Tahapan selanjutnya merupakan tahapan implementasi. Proses implementasi produk perangkat pembelajaran IPA berbasis kearifan lokal Ende-Lio dilakukan dengan teknik peerteaching yang kemudian disertai evaluasi terhadap produk dan proses tersebut. Hasil evaluasi produk padasiklus I mencapai persentase rata-rata sebesar 70\%. Perolehan ini belum mencapai target ketuntasan yang diinginkan, sehingga dilanjutkan siklus II sampai terjadi peningkatan mencapai 92\%. Begitupun halnya aktifitas dan kreatifitas yang teramati menunjukkan adanya peningkatan dari siklus I kesiklus II. Dengan demikian, model ADDIE berbasis kearifan lokal EndeLio dapat meningkatkan kualitas perkuliahan desain pembelajaran IPA pada mahasiswa PGSD Uniflor.

\section{SIMPULAN}

Berdasarkan hasil penelitian, disimpulkan bahwa model ADDIE berbasis kearifan lokal Ende-Lio dapat meningkatkan kualitas perkuliahan desain pembelajaran IPA pada mahasiswa PGSD Uniflor. 


\section{DAFTAR PUSTAKA}

Cheung, L. (2016). Using ADDIE model of instructional design to teach chest radiograph interpretation.Journal of Biomedical Education 2016

Fahmi. (2018). The development of creativity of 5-6 year old children through collage game using natural. International Journal of Multidisciplinary and current research 6

Hien, T.,T.,T. (2016). Why is action research suitable for education?.VNU Journal of Science: Foreign Studies, 25(2)

Holden, J.,T. (2015). An Introduction to the ADDIE Instructional System Design Model.FGDLA(1-17). US: fgdla.us

Hsu, T.,C. (2014). Using the ADDIE model to develop online continuing education courses on caring for nurses in Taiwan. The Journal of Continuing Education in Nursing, 45(3), 124-131.

Muruganantham, G. (2015). Developing of E-content package by using ADDIE model. International Journal of Applied Research, 1(3), 52-54

Nadiyah \& Faaizah. (2015). The development of online project based collaborative learning using ADDIE model. Porcedia-Social and Behavioral Sciences, 195, 1803-1812

Nollmeyerd. (2016). Mapping the domain of subject area integration: Elementary educators' description and practice. International Journal of Learning, Teaching and educational Research, 15 (9)

Whipasith, Narumol \& Sumalee.(2016). The Design of the contents of an e-learning for teaching M.5 English Language using ADDIE model.International Journal of Information and Education Technology, 6(2), 127 